\title{
Vibrio na água e sedimento de viveiros de quatro fazendas de carcinicultura no estado do Ceará, Brasil
}

\author{
Vibrio in pond water and sediment from four shrimp farms in Ceará state, Brazil
}

\section{Regine Helena Silva dos Fernandes VIEIRA ${ }^{1}$; Rafael dos Santos ROCHA ${ }^{2}$; Edirsana Maria Ribeiro de CARVALHO $^{3}$; Oscarina Viana SOUSA ${ }^{4}$; Tereza Cristina Vasconcelos GESTEIRA ${ }^{4}$}

${ }^{1}$ Laboratório de Microbiologia Ambiental e do Pescado do Instituto de Ciências do Mar da Universidade Federal do Ceará, Fortaleza-Ceará

${ }^{2}$ Mestrando do Programa de Pós-Graduação em Engenharia de Pesca do Departamento de Engenharia de Pesca da Universidade Federal do Ceará, Fortaleza-Ceará

${ }^{3}$ Doutorando do Programa de Pós-Graduação em Ciências Marinhas Tropicais do Instituto de Ciências do Mar - LABOMAR, Universidade Federal do Ceará, Fortaleza-Ceará

${ }^{4}$ Instituto de Ciências do Mar da Universidade Federal do Ceará, Fortaleza- Ceará

\begin{abstract}
Resumo
Foram realizadas 16 coletas, oito no período chuvoso e oito no período de estio, em quatro fazendas de carcinicultura do Estado do Ceará, nos estuários dos rios Jaguaribe (fazendas A e B) e Acaraú (fazendas C e D), totalizando 32 amostras. O objetivo da pesquisa foi quantificar e identificar Vibrio spp. nas amostras de água e sedimento. Os valores máximos da Contagem Padrão em Placas (CPP) de Vibrio spp. encontrados para as amostras de água, no período chuvoso, foram de $5.10^{3} \mathrm{UFC} / \mathrm{mL}$ est. e, para o sedimento, de 7,5.10 ${ }^{3} \mathrm{UFC} / \mathrm{g}$ est. No período de estio, a CPP máxima para água foi de $4,35.10^{2} \mathrm{UFC} / \mathrm{mL}$ est. e de $3,55.10^{3} \mathrm{UFC} / \mathrm{g}$ est. para as amostras de sedimento. Foram obtidos 36 isolados de Vibrio: Vibrio spp. (17), V. vulnificus B1(3); V. calviensis (2), V. cholerae (2), V. litoralis (2), V. metschnikovii (2), V. agarivorans (1), V. alginolyticus (1), V. campbellii (1), V. coralliilyticus (1), V. diazotrophicus (1), V. logei (1), V. mediterranei (1), V. vulnificus B2 (1). O conhecimento da presença de espécies, nunca anteriormente isoladas em viveiros de fazendas de carcinicultura, tais como o V. coralliilyticus, V. agarivorans, V. litoralis e V. calviensis são importantes para o monitoramento microbiológico contínuo desses ambientes.
\end{abstract}

Palavras-chave: Camarão marinho. Vibrio spp.. Contagem padrão em placas.

\begin{abstract}
Sixteen collections were taken, eight during rainy season and eight on the draught season in four shrimp farms in Ceará State, from Jaguaribe River (farms A and B) and Acaraú River (farms C and D) estuaries, totalizing 32 samples. The goal of the research was to identify and quantify Vibrio spp. in water and in sediment samples. The maximum Standard Plate Count (SPC) values of Vibrio spp. calculated for the rainy season, from water, was $5.10^{3} \mathrm{CFU} / \mathrm{mL}$ est., and for the sediment 7.5.10 $\mathrm{CFU} / \mathrm{g}$ est.. For the draught season, maximum counting for water was $4.35 .10^{2} \mathrm{CFU} / \mathrm{mL}$ est. and for sediment $3.55 .10^{3} \mathrm{CFU} / \mathrm{g}$ est.. Thirty six strains of Vibrio were isolated: Vibrio spp. (17), V. vulnificus B1(3), V. calviensis (2), V. cholerae (2), V. litoralis (2), V. metschnikovii (2), V. agarivorans (1), V. alginolyticus (1), V. campbellii (1), V. coralliilyticus (1), V. diazotrophicus (1), V. logei (1), V. mediterranei (1), V. vulnificus B2 (1). The isolation of species never previously isolated of shrimp farms, such as V. coralliilyticus, V. agarivorans, V. litoralis and V. calviensis are important for the continuous microbiological monitoring these environments.
\end{abstract}

Keywords: Marine shrimp. Vibrio spp.. Standard count plate.

\section{Introdução}

O cultivo de camarão no Brasil foi iniciado na primeira metade dos anos setenta, adquirindo caráter empresarial no final da década de oitenta. Entretanto, só a partir dos anos noventa, com a introdução da espécie Litopenaeus vannamei, o desenvolvimento processou-se em bases mais sólidas dada a rápida adap-
Correspondência para:

Regine Helena Silva dos Fernandes Vieira

Instituto de Ciências do Mar - Laboratório de Microbiologia Ambiental e

do Pescado

Av. Abolição, 3207, Meireles, Fortaleza, Ceará

Fone: (85)3366-7027.

E-mail: reginevieira@terra.com.br

Recebido: 05/05/2009

Aprovado: 05/08/2010 
tação dessa espécie às condições dos estuários brasileiros e sua aceitação pelos consumidores ${ }^{1}$. Segundo Ceccarelli e Figueira ${ }^{2}$, um dos principais fatores para o sucesso de uma fazenda de camarão é a disponibilidade de água em quantidade e qualidade adequadas ao perfeito funcionamento dos ecossistemas de cultivo e, como sugerem, dependentes do preparo do viveiro. Dessa forma o monitoramento das variáveis ambientais, limitantes ao desenvolvimento bacteriano, é de essencial importância para tomada de decisão pelo produtor ${ }^{1}$.

Nos últimos anos a detecção de doenças infecciosas no cultivo de camarões marinhos teve um efeito devastador, causando colapso na produção de grandes países produtores e desencadeando grandes perdas à indústria. A partir de então, as enfermidades passaram a ser vistas como um obstáculo econômico e uma ameaça à viabilidade da atividade ${ }^{3}$.

A garantia da sanidade dos camarões cultivados envolve várias práticas que visam à manutenção da qualidade da água e a redução do estresse dos animais, que poderiam favorecer o desencadeamento de enfermidades causadas por patógenos oportunistas ${ }^{4}$. Devido à rápida expansão do cultivo, a atividade está sendo ameaçada por doenças provocadas por bactérias do gênero Vibrio, que afetam a sobrevivência e o crescimento dos camarões ${ }^{5}$. Segundo Lightner ${ }^{6}$ os víbrios fazem parte da microbiota natural dos camarões, podendo representar risco ao cultivo quando da instalação de condições ambientais adversas, sendo considerados os principais patógenos bacterianos dessa atividade. Se veiculados a produtos destinados ao consumo, podem provocar desde gastrenterites a quadros de septicemia.

De acordo com Barbieri et al. ${ }^{7}$, os ambientes estuarinos são reservatórios críticos para espécies do gênero Vibrio causadoras de doenças e, uma vez que as fazendas de carcinicultura utilizam a água dos estuários para o cultivo, o monitoramento microbiológico das mesmas se faz necessário.
Dessa forma, o presente trabalho teve como objetivo quantificar, através da técnica de contagem padrão em placas (CPP), e identificar as espécies do gênero Vibrio presentes em amostras de água e sedimento de quatro fazendas de carcinicultura do Estado do Ceará.

\section{Material e Método}

As coletas foram realizadas em quatro fazendas de cultivo de Litopenaeus vannamei: duas fazendas (A e B) localizadas no estuário do rio Jaguaribe, litoral leste do Estado do Ceará, e duas (C e D) no estuário do rio Acaraú, litoral oeste. Foram coletadas oito amostras de água e oito de sedimento em dois períodos: chuvoso e de estiagem, de março a junho e de agosto a novembro de 2008 , respectivamente, totalizando 16 coletas e 32 amostras.

As amostras de água e sedimento corresponderam a quatro subamostras ( $p o o l$ ) obtidas em locais diferentes do viveiro. Para a coleta da água, utilizou-se uma garrafa de cor âmbar de $1 \mathrm{~L}$, previamente esterilizada. As amostras de sedimento foram obtidas com um coletor simplificado de sedimento, sendo as quatro subamostras homogeneizadas com colher estéril e armazenadas em Becker de $500 \mathrm{~mL}$ esterilizado. As amostras de água e sedimento foram acondicionadas em caixas isotérmicas e transportadas para o Laboratório de Microbiologia Ambiental e do Pescado, do Instituto de Ciências do Mar (Labomar), da Universidade Federal do Ceará, e imediatamente processadas.

A garrafa com água em temperatura ambiente foi agitada para promover a suspensão do material. Com o auxílio de um pipetador automático, foi retirada uma alíquota de $1 \mathrm{~mL}$ e diluída em $9 \mathrm{~mL}$ de solução salina 1,0\% em um tubo de ensaio, que correspondeu à diluição de $10^{-1}$. Dessa diluição $10^{-1}$, foi retirado 1 $\mathrm{mL}$ e repassado para outro tubo de ensaio com $9 \mathrm{~mL}$ de salina $1,0 \%$, correspondendo a diluição $10^{-2}$. O procedimento foi repetido sucessivamente até a diluição de $10^{-4} 8$. 
Foram pesados $50 \mathrm{~g}$ das amostras de sedimento e colocados em Erlenmeyer com $450 \mathrm{~mL}$ de solução salina $1,0 \%$, correspondendo à diluição de $10^{-1}$. A amostra foi agitada por 30 minutos em agitador magnético, a fim de se promover a suspensão do material preso ao sedimento. Foram realizadas sucessivas diluições, até a diluição de $10^{-48}$.

A partir das diluições das amostras de água e sedimento, foi retirada uma alíquota de $200 \mu \mathrm{L}$ de cada diluição, e espalhada com alça de Drigalsky em placas de Petri com Ágar Tiossulfato-Citrato-Bile-Sacarose (TCBS), em duplicata, sendo incubadas em estufa a $35^{\circ} \mathrm{C} / 24 \mathrm{~h}^{8}$. As placas que apresentaram crescimento de colônias sacarose positivas (amarelas) e/ou negativas (verdes) foram consideradas presuntivas quanto à presença de Vibrio $^{8}$.

Placas com número de colônias $<25$ e $>250$ tiveram suas contagens estimadas (est.). Foram selecionadas de três a cinco colônias das placas de TCBS, estriadas em Ágar Triptona-Soja (TSA), incubadas em estufa a $35^{\circ} \mathrm{C} / 24 \mathrm{~h}$, e acondicionadas em estufa B.O.D. para as etapas posteriores ${ }^{8}$.

Para identificação das cepas de Vibrio spp. foi utilizada a chave fenotípica de Noguerola e Blanch ${ }^{9}$. Esta chave apresenta oito clusters, ou agrupamentos, sendo diferenciados pelos resultados, positivo ou negativo, dos aminoácidos arginina (A), lisina (L) e ornitina (O). Dessa forma têm-se os agrupamentos: $\mathrm{A}+/ \mathrm{L}+/$ $\mathrm{O}+, \mathrm{A}+/ \mathrm{L}+/ \mathrm{O}-, \mathrm{A}+/ \mathrm{L}-/ \mathrm{O}-, \mathrm{A}-/ \mathrm{L}-/ \mathrm{O}-, \mathrm{A}-/ \mathrm{L}-/ \mathrm{O}+$, $\mathrm{A}-/ \mathrm{L}+/ \mathrm{O}+, \mathrm{A}+/ \mathrm{L}-/ \mathrm{O}+$ e $\mathrm{A}-/ \mathrm{L}+/ \mathrm{O}-$. De posse dos resultados do teste dos três aminoácidos, para cada cepa, partiu-se de um agrupamento com posterior uso dos testes bioquímicos para identificação.

A partir da entrada na chave, foram realizados os testes específicos para cada cepa: crescimento a $0,3,6$, 8 e $10 \%$ de $\mathrm{NaCl}$, crescimento a $4,20,30,35$ e $40{ }^{\circ} \mathrm{C}$, citrato, gelatinase, indol, $\mathrm{NO}_{2}, \mathrm{ONPG}$, oxidase, urease, VP, sacarose, manitol e resistência a ampicilina $10 \mu \mathrm{g}^{9}$.

As variáveis físico-químicas: salinidade (água) e $\mathrm{pH}$ (água e sedimento) foram determinadas in situ, en- quanto a temperatura da água foi determinada in locu durante cada amostragem.

Os resultados de CPP de Vibrio spp. da água e sedimento foram submetidos à análise de variância ( $a$ $=5 \%$ ), utilizando-se o programa Statistica versão 7.0, para comparação das contagens entre as fazendas nos dois períodos estudados. Nos casos em que a homocedasticidade não foi constatada, os dados foram logaritmizados. As variáveis físico-químicas analisadas: temperatura da água, $\mathrm{pH}$ (da água e sedimento) e salinidade da água também foram submetidas à análise de variância $(\alpha=5 \%)$. Foi realizado teste de correlação entre os resultados da CPP de Vibrio spp. e as variáveis físico-químicas analisadas $(\alpha=5 \%)$.

\section{Resultados}

Os resultados da CPP de Vibrio spp. da água e sedimento dos viveiros das quatros fazendas de carcinicultura analisadas, e as variáveis físico-químicas no período estudado são apresentados na tabela 1 .

A fazenda $\mathrm{A}$, somente na primeira coleta (período chuvoso), apresentou valor de CPP de Vibrio spp. do sedimento estatisticamente superior as demais ( $\mathrm{p}$ $<0,05)$, enquanto a CPP de Vibrio spp. da água não apresentou diferença significativa entre as fazendas analisadas $(\mathrm{p}>0,05)$ nos dois períodos estudados ( $\mathrm{Fi}$ gura 1).

A temperatura e o $\mathrm{pH}$ da água e sedimento não apresentaram variação significativa no experimento (Tabela 1). Os resultados da salinidade, na fazenda $\mathrm{A}$ durante o período chuvoso foram inferiores aos demais $(\mathrm{p}<0,05)$. Não foi verificada correlação entre as variáveis físico-químicas analisadas e as respectivas contagens de Vibrio spp. para água e sedimento, nos dois períodos estudados, nas quatro fazendas.

Foram obtidos 36 isolados de Vibrio, dos quais 27 foram oriundos da água: Vibrio spp. (12), V.calviensis (2), V. litoralis (2), V. metschnikovii (2), V. agarivorans (1), $V$. alginolyticus (1), $V$. cholerae (1), V. campbellii (1), $V$. 
Tabela 1 - Contagem Padrão em Placas (CPP) de Vibrio spp. das amostras de água e sedimento de viveiros e variáveis físico-químicas das quatro fazendas de carcinicultura (A, B no Estuário do Rio Jaguaribe e C, D no Estuário do rio Acaraú, Estado do Ceará) no período chuvoso e de estiagem

\begin{tabular}{|c|c|c|c|c|c|c|c|c|}
\hline \multirow{2}{*}{\multicolumn{2}{|c|}{ Coletas (Fazenda) }} & \multirow[b]{2}{*}{ Hora } & \multicolumn{4}{|c|}{ Variáveis-Físico-Químicas } & \multicolumn{2}{|c|}{ CPP } \\
\hline & & & $\mathrm{T}\left({ }^{\circ} \mathrm{C}\right)$ & S (\%o) & pH Água & pH Sedimento & Água (UFC/mL) & Sedimento (UFC/g) \\
\hline \multirow{8}{*}{$\begin{array}{l}0 \\
0 \\
0 \\
3 \\
3 \\
0\end{array}$} & $01(\mathrm{~A})$ & $10: 30$ & 30 & 4 & 8,65 & 8,44 & $<300^{*}$ & $3.000-7.500$ \\
\hline & $02(\mathrm{~B})$ & $12: 30$ & 30 & 15 & 8,75 & 6,52 & $<50^{*}$ & $175-500^{*}$ \\
\hline & $03(\mathrm{C})$ & 15:00 & 30 & 27 & 7,92 & 7,32 & $250-5.000^{\star}$ & $<25^{\star}$ \\
\hline & $04(\mathrm{D})$ & 09:00 & 30 & 29 & 8,40 & 6,57 & $425^{\star}$ & $<25^{*}$ \\
\hline & $05(\mathrm{~A})$ & $10: 00$ & 28 & 4 & 8,27 & 5,95 & $<25^{*}$ & $<25^{\star}$ \\
\hline & 06(B) & $10: 20$ & 28 & 18 & 8,80 & 7,52 & $75^{*}$ & $<25^{*}$ \\
\hline & $07(\mathrm{C})$ & $10: 00$ & 29 & 40 & 8,09 & 8,05 & $150^{*}$ & $<50^{*}$ \\
\hline & $08(\mathrm{D})$ & 09:45 & 29 & 38 & 8,18 & 7,79 & $<225^{\star}$ & $150-5.000$ \\
\hline \multirow{8}{*}{$\stackrel{0}{\circ}$} & 09(B) & $10: 40$ & 28 & 34 & 8,42 & 6,96 & $150^{*}$ & $<50^{*}$ \\
\hline & $10(\mathrm{C})$ & 09:30 & 28 & 47 & 8,03 & 7,27 & $300-500^{*}$ & $<25^{\star}$ \\
\hline & $11(\mathrm{D})$ & $10: 00$ & 29 & 35 & 8,27 & 7,43 & $<25^{*}$ & $<25^{*}$ \\
\hline & $12(\mathrm{~A})$ & 09:45 & 30 & 30 & 8,05 & 6,82 & $50-575^{\star}$ & $<25^{\star}$ \\
\hline & $13(\mathrm{C})$ & 10:00 & 30 & 46 & 7,83 & 7,11 & $<25^{*}$ & $<25-100^{*}$ \\
\hline & $14(\mathrm{D})$ & $10: 30$ & 29 & 50 & 8,21 & 7,61 & $<25^{*}$ & $<25^{*}$ \\
\hline & $15(\mathrm{~A})$ & $10: 00$ & 25 & 35 & 8,18 & 7,00 & $<435^{*}$ & $<3.550^{*}$ \\
\hline & $16(\mathrm{~B})$ & $10: 00$ & 28 & 51 & 7,94 & 7,11 & $<350^{*}$ & $<50^{*}$ \\
\hline
\end{tabular}

${ }^{*}$ contagens estimadas

vulnificus B1(1), V. coralliilyticus (1), V. diazotrophicus (1), V. logei (1), V. mediterranei (1), e nove (9) do sedimento: Vibrio spp. (5), V. vulnificus B1(2); V. cholerae (1), V. vulnificus B2 (1).

\section{Discussão}

No geral, os valores das CPP's de Vibrio spp. nas amostras de água e de sedimento dos viveiros, tanto nas fazendas abastecidas pelo Rio Jaguaribe, quanto nas abastecidas pelo Rio Acaraú foram considerados baixos quando comparados a um estudo prévio feito por Martins ${ }^{10}$. É possível que a distância do local da coleta e o tempo gasto no transporte tenham estressado as células impedindo-as de se multiplicar. Foi demonstrado que os víbrios são capazes de responder a condições ambientais adversas entrando numa fase viável, mas não cultivável $(\mathrm{VNC})^{11}$. Isto pode acontecer quando as bactérias são expostas a situações indesejáveis de salinidade, de temperatura ou de privação de nutrientes, podendo ser danificadas reversivelmente, não sendo detectáveis por métodos bacteriológicos padrões. Contudo, se lhe são proporcionadas condições ótimas para sua proliferação, podem voltar ao estado cultivável ${ }^{12}$.

As elevadas temperaturas e a pequena amplitude térmica apresentada durante todo o período amostrado podem ser consideradas normais para as regiões tropicais e, nessas condições, o desenvolvimento de 

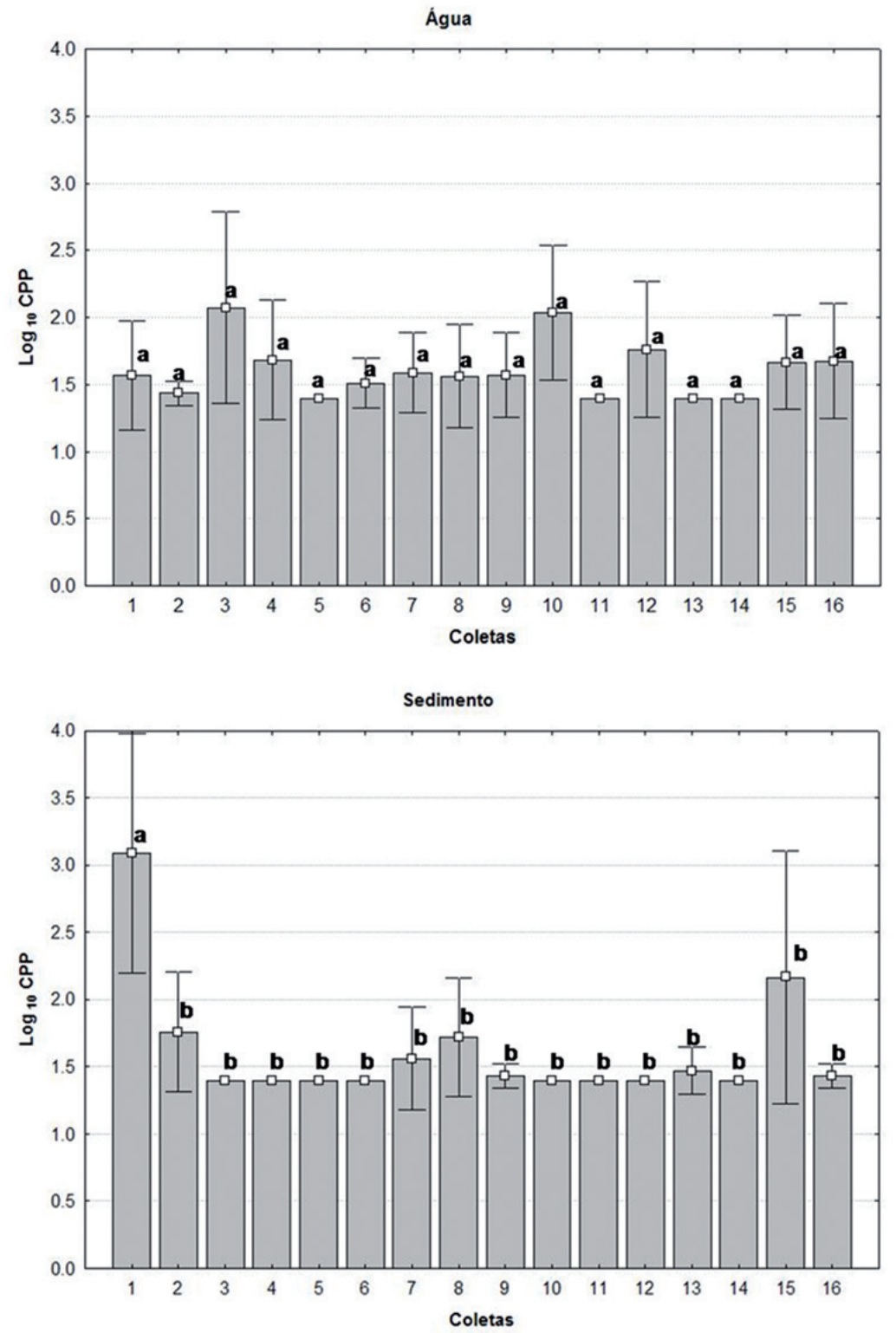

Figura 1 - Média dos resultados logaritmizados da Contagem Padrão em Placas (CPP) de Vibrio em amostras de água e sedimento de viveiro de quatro fazendas de carcinicultura analisadas: Fazenda A (1,5,12 e15), Fazenda B (2,6,9 e16), Fazenda C (3,7.10 e 13) e Fazenda D $(4,8,11$ e 14$)$ no período chuvoso (1-8) e de estiagem (9-16) (letras iguais nas colunas representam valores estatisticamente iguais $(\mathrm{p}>0,05$; letras diferentes nas colunas representam valores estatisticamente diferentes $\mathrm{p}<0,05)$

bactérias mesófilas, em particular as do gênero $\mathrm{Vi}$ brio, é favorecido ${ }^{13}$. De acordo com Huss, Ababouch e $\mathrm{Gram}^{14}$ todas as espécies pertencentes ao gênero $\mathrm{Vi}$ brio são típicas de ambientes marinhos e estuarinos, com necessidade de 2 a $3 \%$ de $\mathrm{NaCl}$ para o seu crescimento, com pH ótimo entre 7,8 e $8,5^{15}$.
Arana $^{16}$ correlacionou a precipitação em regiões tropicais com a redução da salinidade da água em tanques de cultivo, intensificação de processos químicos no sedimento e redução na diversidade bacteriana halofílica. Já Lipp, Huq e Colwell ${ }^{17}$ consideraram o período chuvoso como determinante ambiental de 
sumária importância para a sobrevivência de Vibrio. No presente estudo, não houve diferença significativa entre as amostras e os períodos de estio e chuvoso. Talvez os baixos resultados nas contagens de víbrios, na maior parte das coletas, possam ter influenciado nos testes estatísticos (Tabela 1 e Figura 1) como constatado na ausência de correlação entre estas e as variáveis físico-químicas e as contagens.

Hervio-Heath et al. ${ }^{18}$ relataram que no período isento de chuvas (estio) a diversidade e isolamento de Vibrio tende a ser maior, o que no presente trabalho pode ser constatado. $\mathrm{Lima}^{19}$, pesquisando a diversidade de Vibrio spp em viveiros de fazendas de carcinicultura cearenses, notificou a presença das espécies $V$. alginolyticus $e V$. mediterranei, também relatados no presente estudo.

Foram isoladas espécies de Vibrio diferentes das habitualmente encontradas em ambientes de carcinicultura, tais como o $V$. coralliilyticus, $V$. agarivorans, $V$. litoralis e V. calviensis. Este fato serve de alerta para os carciniculturores, uma vez que não se tem o conheci-

\section{Referências}

1. ASSOCIAČ̃̃O BRASILEIRA DOS CRIADORES DE CAMARÃO MARINHO. O agronegócio do camarão marinho cultivado. Recife: ABCCM, 2002. 20 p.

2. CECCARELLI, P. S.; FIGUEIRA, L. B. Possíveis problemas de saúde devido ao uso de excretas na aqüicultura. Panorama da Aquicultura, v. 11, n. 63, p. 38-40, 2001

3. NUNES, A. J. P.; MARTINS, P. C. Avaliando o estado de saúde de camarões marinhos na engorda. Panorama da Aquicultura, v. 12, n. 72, p. 23-33, 2002.

4. OKOH, A. I.; IGBINOSA, E. O. Emerging Vibrio species: an unending threat to public health in developing countries. Research in Microbiology, v. 159, n. 7/8, p. 495-506, 2008.

5. AGUIRRE-GUZMÁN, G.; VAZQUEZ-JUAREZ, R. ASCENCIO, F. Differences in the susceptibility of american white shrimp larval substages (Litopenaeus vannamei) to four Vibrio species. Journal of Invertebrate Pathology, v. 78, n. 4, p. $215-219,2001$.

6. LIGHTNER, D. V. Diseases of penaeid shrimp. In: MCVEY, J. P. (Ed.). Handbook of mariculture: crustacean aquaculture. Boca Raton: CRC Press, 1996. p. 393-486.

7. BARBIERI, E.; FALZANO, L.; FIORENTINI, C.; PIANETTI, A.; BAFFONE, W.; FABBRI, A.; MATARRESE, P.; CASIERE, A.; KATOULI, M.; KÜHN, I.; MÖLLBY, R.; BRUSCOLINI, F.; DONELLI, G. Occurrence, diversity, and pathogenicity of halophilic Vibrio spp. and non-O1 Vibrio cholerae from estuarine waters along the Italian Adriatic coast. Journal mento da patogenicidade dessas ao animal cultivado. Ben-Haim et al..$^{20}$ associaram um alto grau de patogenicidade a $V$. coralliilyticus, uma vez que essa espécie foi isolada de corais doentes da espécie Pocillopora damicornis.

\section{Conclusão}

Apesar dos valores da CPP de Vibrio spp. da água e sedimento dos viveiros terem se apresentado baixos durante todo o período estudado, um fato que chamou a atenção foi a identificação de espécies nunca anteriormente isoladas do ambiente de carcinicultura: V. corallilyticus, $V$. agarivorans, $V$. litoralis e $V$. calviensis.

\section{Agradecimentos}

Os autores agradecem ao Conselho Nacional de Pesquisa, CNPq, pela bolsa de Iniciação Científica conferida ao Engenheiro de Pesca Rafael dos Santos Rocha para realização do trabalho.

Applied Microbiology, v. 65, n. 6, p. 2748-2753, 1999.

8. DOWNES, M. P.; ITO, K. Compendium of methods for the microbiological examination of foods. 4. ed. Washington DC: APHA, 2001. 600 p.

9. NOGUEROLA, I.; BLANCH, A. R. Identification of Vibrio spp. with a set of dichotomous keys. Journal of Applied Microbiology, v. 105, n. 1, p. 175-185, 2008.

10.MARTINS, P. C. C. Influência das condições ambientais e das técnicas do manejo de produção sobre a ocorrência de enfermidades no cultivo de camarão marinho Litopenaeus vannamei, no Estado do Ceará, 2003. 117 f. Tese (Doutorado em Ecologia e Recursos Naturais) - Universidade Federal de São Carlos, São Paulo, 2003.

11.BAFFONE, W.; CITTERIO, B.; VITTORIA, E.; CASAROLI, A.; CAMPANA, R.; FALZANO, L.; DONELLI, G. Retention of virulence in viable but non-culturable halophilic Vibrio spp. International Journal of Food Microbiology, v. 89, p. 31-39, 2003

12.HUSS, H. H. Assurance of sea food quality. Roma: FAO, 1993. 169 p. (FAO Fisheries Technicl Paper, 334).

13.CERVINO, J. M.; HAYES, R. L.; POLSON, S. W.; POLSON, S. C.; GOREAU, T. J.; MARTINEZ, R. J.; SMITH, G. W. Relationship of Vibrio species infection and elevated temperatures to yellow blotch/band disease in Caribbean corals. Applied Environmental Microbiology, v. 70, n. 11, p. 6855-6864, 2004. 
14.HUSS, H. H.; ABABOUCH, L.; GRAM, L. Assessment and management of seafood safety and quality. Roma: FAO, 2003. 230 p. (FAO Fisheries Technical Paper 444).

15.LAKE, R.; HUDSON, A.; CRESSEY, P. Risk profile: Vibrio parahaemolyticus in seafood. Christchurch: Crown Research Institute, 2003. $54 \mathrm{p}$.

16. ARANA, L. V. Princípios químicos da qualidade da água em aquicultura. Florianópolis: Editora da UFSC, 1999. 166 p.

17.LIP, E. K.; HUQ, A.; COLWELL, R. R. Effects of global climate on infections disease: the Cholera model. Clinical Microbiology Reviews, v.15, n. 4, p. 757-770, 2002.

18.HERVIO-HEATH, D.; COLWELL, R. R.; DERRIEN, A.;
ROBERT-PILOT, A.; FOURNIER, J. M.; POMMEPUY, M. Occurrence of pathogenic vibrios in coastal areas of France. Journal of Applied Microbiology, v. 92, p. 1123-1135, 2002.

19. LIMA, A. S. Vibrio em camarão e na água de três fazendas de carcinicultura do Ceará. 2007. 123 f. Dissertação (Mestrado em Ciências Marinhas Tropicais) - Instituto de Ciências do Mar, Universidade Federal do Ceará, Ceará, 2007.

20.BEN-HAIM, Y.; THOMPSON, F. L.; THOMPSON, C. C.; CNOKAERT, M. C.; HOSTE, B.; SWINGS, J.; ROSENBERG, E. Vibrio coralliilyticus sp. nov., a temperature - dependent pathogen of the coral Pocillopora damicornis. International Journal of Systematic and Evolutionary Microbiology, v. 53, p. 309-315, 2003. 